\title{
COVID-19 pandemic and stent thrombosis in a post percutaneous coronary intervention patient-a case report highlighting the selection of P2Y12 inhibitor
}

\author{
Rahul Choudhary^, Atul Kaushik, Jai Bharat Sharma \\ All India Institute of Medical Sciences, Jodhpur, India \\ Correspondence to: Rahul Choudhary. All India Institute of Medical Sciences, Jodhpur, India. Email: drrahulchoudhary@yahoo.com.
}

\begin{abstract}
The current pandemic of novel coronavirus disease 2019 (COVID-19) has posed a great threat to people's health worldwide, with specific implications on patients with underlying heart diseases. During this challenging period, nearly all major societies have recommended for conservative approach, even for patients with relatively stable acute cardiovascular diseases. Selection of specific antiplatelet therapy in an uncomplicated post percutaneous coronary intervention (PCI) patient can, at times, be crucial issue in such strained circumstances. We report a case of 64-year-old male, who was taken for urgent coronary angiogram (CAG) in view of non ST elevation acute coronary syndrome. Successful PCI with implantation of drug eluting stent was done for right coronary artery (RCA) and left anterior descending (LAD) artery lesions. On day 5th post-PCI, he developed acute inferior wall STEMI due to subacute stent thrombosis (ST), and despite all efforts, patient could not be saved as he didn't receive timely intervention. Increased travel time to emergency department due to lockdown because of COVID-19 and along with extra time required for donning of personal protection equipment (PPE) and other COVID-19 related safety measures prolonged the ischemic time. Potent P2Y12 inhibitor based dual antiplatelet therapy might have prevented this subacute ST, and thus mortality, as the patient was discharged on clopidogrel after PCI. While selecting specific P2Y12 inhibitor in a post PCI patient, apart from clinical condition of patient and complexity of procedure, we should also consider current COVID-19 pandemic. Current circumstances may favour ticagrelor over other P2Y12 inhibitors in view of its potent, rapid, and reversible antiplatelet action along with its optimistic effect in pneumonia.
\end{abstract}

Keywords: Stent thrombosis (ST); P2Y12 inhibitor; COVID-19; acute coronary syndrome; case report

Submitted May 05, 2020. Accepted for publication Jul 06, 2020.

doi: $10.21037 / \mathrm{cdt}-20-485$

View this article at: http://dx.doi.org/10.21037/cdt-20-485

\section{Introduction}

The current pandemic of novel coronavirus disease 2019 (COVID-19) has posed a great threat to people's health worldwide, with specific implications on patients with underlying heart diseases. During this challenging period, nearly all major societies have recommended for conservative approach, even for patients with relatively stable acute cardiovascular diseases (1). Selection of specific antiplatelet therapy in an uncomplicated post percutaneous coronary intervention (PCI) patient can, at times, be crucial issue in such strained circumstances. We report a case of fatal stent thrombosis (ST) in a patient having acute coronary syndrome, which might have been appropriately managed during non-pandemic period.

We present the following article in accordance with the CARE reporting checklist (available at http://dx.doi.

\footnotetext{
^ ORCID: 0000-0002-5013-5734.
} 
org/10.21037/cdt-20-485).

\section{Case presentation}

A 64-year-old male patient presented to emergency department with non-ST elevation acute coronary syndrome (NSTEACS). He was taken for urgent coronary angiogram (CAG), as his chest pain continued despite optimal medical therapy, which revealed double vessel disease. Successful PCI was done for right coronary artery (RCA) and left anterior descending (LAD) artery lesions, with implantation of one drug eluting stent in each of the coronary artery (Figure 1A,B,C). Patient was discharged on day $3^{\text {rd }}$ with advice to take aspirin, clopidogrel, atorvastatin, ramipril and long acting metoprolol. On day $5^{\text {th }}$, patient complained of severe chest pain and syncope, for which he consulted nearby physician. Electrocardiogram (ECG) showed acute inferior wall ST elevation myocardial infarction (IWSTEMI) with complete heart block $(\mathrm{CHB})$ and the patient was immediately referred to our emergency department. On a routine day, travel time from his residential area to emergency department of our institute is almost 2 hours, but due to restrictions in view of COVID-19 lockdown, it took around 4 hrs to reach emergency department. Patient was semi-conscious at the time of presentation; his $\mathrm{BP}$ was $60 / 40 \mathrm{~mm}$ of $\mathrm{Hg}$ with a pulse rate of $34 \mathrm{bpm}$. Keeping RCA ST as a probable cause, activation of cardiac catheterization lab (CCL) was done. CAG showed thrombotic occlusion of RCA stent, for which aspiration thrombectomy was done (Figure 1D, Video 1). But despite all efforts, patient could not be saved. STEMI diagnosis to wire crossing time was 55 minutes (much longer than our institutional mean of 36 minutes in non COVID-19 situation); extra time being required for donning of personal protection equipment (PPE) and other COVID-19 related safety measures (Table 1).

All procedures performed in studies involving human participants were in accordance with the ethical standards of the institutional and/or national research committee(s) and with the Helsinki Declaration (as revised in 2013). Written consent for submission and publication of this case report including image(s) and associated text has been obtained from the patient in line with COPE guidance.

\section{Discussion}

$\mathrm{ST}$ is an uncommon but most dreaded complication of coronary artery stenting, usually presents as acute STEMI and carries a 30 -day mortality rate of $20 \%$ to $45 \%$ (2). The mechanisms of underlying sent thrombosis are multifactorial; include patient-related factors (diabetes mellitus, renal failure), procedural factors (the complexity of the lesion, bifurcating lesions and poor stent expansion and apposition to vessel wall) and post-procedural factors (type and duration of antiplatelet therapy). Although we don't know the exact cause of thrombosis in our case, but patient was non-diabetic with normal renal function and the end result of PCI was satisfying with adequate stent expansion.

The outbreak of severe acute respiratory syndrome 2 (SARS-CoV-2) has placed unprecedented strain on health care services worldwide. Even cardiologists are unable to perform primary PCI within the stipulated time intervals as both prehospital and hospital delays are grossly increased during COVID-19 pandemic. Tam et al. reported that median pre-hospital delay has increased from 82.5 to 318 minutes and door to device time has increased from 84.5 to 110 minutes (3). People are reluctant to seek medical care during the COVID-19 outbreak, which explains the increase in prehospital delay. Similarly, even after patient arrives in the CCL, staff, technician and cardiologist may need more time to wear PPE and to prepare the patients for procedure, leading to longer door to device time. ST, which has got high mortality rates even on routine working days, will have grave consequences during lock down states, as management of ST demands timely diagnosis and prompt procedure to prevent mortality and morbidity.

Insufficient antiplatelet, along with ACS presentation, is cardinal risk factor for ST. Prevalence of clopidogrel resistance in our country various between $5-44 \%$ and we cannot rule out drug resistance in our case (4). The other two $\mathrm{P}_{2} \mathrm{Y}_{12}$ inhibitors, apart from clopidogrel, were associated with a marked reduction in ST in the pivotal clinical trials. The PLATO study showed a 33\% reduction in the 1-year incidence of definite ST with ticagrelor vs. clopidogrel, which was later confirmed in the SWEDEHEART registry $(5,6)$. In the TRITON study, the 15 -month incidence of definite ST was $2.2 \%$ in the clopidogrel group but $1.1 \%$ in the prasugrel group (7). As the ongoing lockdown conditions hampers the timely diagnosis and management of ST, it is beneficial to enhance antiplatelet therapy so as to reduce incidence of ST in present state of near complete lockdown. This strategy needs to carefully weigh the balance between patient benefit and increased bleeding risk. Once all contraindication for ticagrelor or prasugrel are ruled out, one should have low threshold for using 

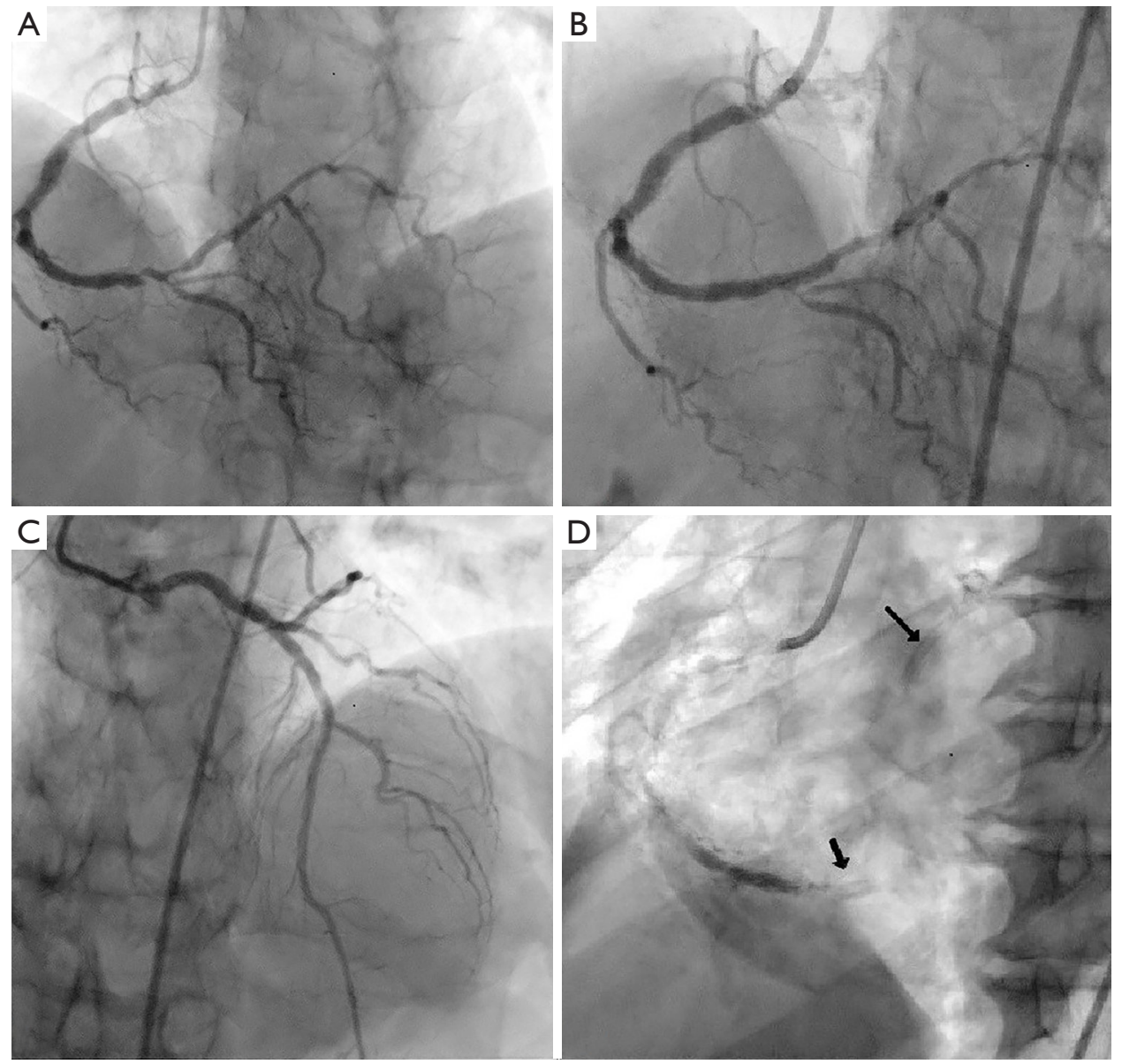

Figure 1 Cineangiogram images of Right and Left coronary artery. (A) Coronary angiography on LAO cranial view shows significant lesion in distal right coronary artery with involvement of posterior left ventricular branch and posterior descending artery. (B) Coronary angiography on LAO cranial view shows right coronary artery after stent implantation. (C) Coronary angiography on AP cranial view shows left coronary artery after stent implantation. (D) Coronary angiography on LAO cranial view shows stent thrombosis in RCA. Black arrows show stent in LAD and RCA. AP, anteroposterior; LAO, left anterior oblique.

one of them and avoid clopidogrel altogether, particularly when PCI is performed in ACS settings.

Ticagrelor, like all $\mathrm{P} 2 \mathrm{Y}_{12}$ inhibitors, reduce platelet leukocyte aggregates and release of platelet-derived proinflammatory cytokines from $\alpha$-granules, but additionally also inhibit cellular adenosine uptake by inhibiting nucleoside transporter (NT). Therefore, in comparison to clopidogrel and prasugrel, this unique property of dual inhibition of platelet $\mathrm{P} 2 \mathrm{Y}_{12}$ receptor and NT, ticagrelor confers more potent anti-inflammatory properties. Furthermore, evidence regarding clinical benefit of ticagrelor in the management of pneumonia by preventing the septic complications and reducing lung injury, were provided by the Targeting Platelet-Leukocyte Aggregates in Pneumonia with Ticagrelortrial and post-hoc analyses of PLATO study $(8,9)$. This additional action might be beneficial, if a post PCI patient on ticagrelor therapy develops pneumonia due to COVID-19.

\section{Conclusions}

While selecting specific $\mathrm{P} 2 \mathrm{Y}_{12}$ inhibitor in a post PCI patient, apart from clinical condition of patient and complexity of procedure, we should also consider current COVID-19 pandemic. Current circumstances may favour ticagrelor over other $\mathrm{P} 2 \mathrm{Y}_{12}$ inhibitors in view of its potent, rapid, and reversible antiplatelet action along with its optimistic effect in pneumonia. 
Table 1 Timeline

\begin{tabular}{ll}
\hline Initial procedure & $\mathrm{PCl}$ of RCA and LAD done with implantation of drug eluting stent \\
\hline Day $5^{\text {th }}$ post-procedure & Patient developed acute inferior wall STEMI associated with complete heart block and hypotension \\
Day $5^{\text {th }}$ post-procedure, 4 hours after & Cineangiogram showed subacute stent thrombosis, despite all efforts, patient collapsed \\
Acute inferior wall STEMI & \\
\hline
\end{tabular}

\section{Acknowledgments}

Funding: None.

\section{Footnote}

Reporting Checklist: The authors present the study in accordance with the CARE reporting checklist. Available at http://dx.doi.org/10.21037/cdt-20-485

Conflicts of Interest: All authors have completed the ICMJE uniform disclosure form (available at http://dx.doi. org/10.21037/cdt-20-485). The authors have no conflicts of interest to declare.

Ethical Statement: The authors are accountable for all aspects of the work in ensuring that questions related to the accuracy or integrity of any part of the work are appropriately investigated and resolved. All procedures performed in studies involving human participants were in accordance with the ethical standards of the institutional and/or national research committee(s) and with the Helsinki Declaration (as revised in 2013). Written consent for submission and publication of this case report including image(s) and associated text has been obtained from the patient in line with COPE guidance.

Open Access Statement: This is an Open Access article distributed in accordance with the Creative Commons Attribution-NonCommercial-NoDerivs 4.0 International License (CC BY-NC-ND 4.0), which permits the noncommercial replication and distribution of the article with the strict proviso that no changes or edits are made and the original work is properly cited (including links to both the formal publication through the relevant DOI and the license). See: https://creativecommons.org/licenses/by-nc-nd/4.0/.

\section{References}

1. Welt FGP, Shah PB, Aronow HD, et al. Catheterization
Laboratory Considerations During the Coronavirus (COVID-19) Pandemic: From the ACC's Interventional Council and SCAI. J Am Coll Cardiol 2020;75:2372-5.

2. Mauri L, Hsieh WH, Massaro JM, et al. Stent thrombosis in randomized clinical trials of drug-eluting stents. $\mathrm{N}$ Engl J Med 2007;356:1020-9.

3. Tam CF, Cheung KS, Lam S, et al. Impact of Coronavirus Disease 2019 (COVID-19) Outbreak on ST-Segment-Elevation Myocardial Infarction Care in Hong Kong, China. Circ Cardiovasc Qual Outcomes 2020;13:e006631.

4. Ray S. Clopidogrel resistance: the way forward. Indian Heart J 2014;66:530-4.

5. Wallentin L, Becker RC, Budaj A, et al. Ticagrelor versus clopidogrel in patients with acute coronary syndromes. $\mathrm{N}$ Engl J Med 2009;361:1045-57.

6. Sahlén A, Varenhorst C, Lagerqvist B, et al. Outcomes in patients treated with ticagrelor or clopidogrel after acute myocardial infarction: experiences from SWEDEHEART registry. Eur Heart J 2016;37:3335-42.

7. Wiviott SD, Braunwald E, McCabe CH, et al. Prasugrel versus clopidogrel in patients with acute coronary syndromes. N Engl J Med 2007;357:2001-15.

8. Sexton TR, Zhang G, Macaulay TE, et al. Ticagrelor Reduces Thromboinflammatory Markers in Patients With Pneumonia. JACC Basic Transl Sci 2018;3:435-49.

9. Storey RF, James SK, Siegbahn A, et al. Lower mortality following pulmonary adverse events and sepsis with ticagrelor compared to clopidogrel in the PLATO study. Platelets 2014;25:517-25.

Cite this article as: Choudhary R, Kaushik A, Sharma JB. COVID-19 pandemic and stent thrombosis in a post percutaneous coronary intervention patient-a case report highlighting the selection of P2Y12 inhibitor. Cardiovasc Diagn Ther 2020;10(4):898-901. doi: 10.21037/cdt-20-485 